\title{
PENGUATAN UMKM MARTABAK SURBAN SYABAN SAMARINDA KALIMANTAN TIMUR DI MASA PANDEMI
}

\author{
Rudy Agung Nugroho', Yudha Aulia Firnanda ${ }^{1}$, Hadi Purwo Wiyono ${ }^{3}$, Ilmania Laora Sunan \\ Tias $^{4}$, dan Nuraeni Muzdalifah ${ }^{5}$ \\ ${ }^{1}$ Jurusan Biologi, Fakultas MIPA, Universitas Mulawarman, Samarinda \\ ${ }^{2}$ Fakultas Pertanian, Universitas Mulawarman, Samarinda \\ ${ }^{3}$ Fakultas Ilmu Sosial dan Ilmu Politik, Universitas Mulawarman, Samarinda \\ ${ }^{4}$ Fakultas Ekonomi dan Bisnis, Universitas Mulawarman, Samarinda \\ ${ }^{5}$ Fakultas Hukum, Universitas Mulawarman, Samarinda
}

rudyagung.nugroho@fmipa.unmul.ac.id,yudhauliaf@gmail.com, hadiwiyono885@gmail.com,niailmania@gmail.com, nuraenimuzdalifah055@gmail.com

\begin{abstract}
Abstrak
Masa pandemi adalah masa yang berat bagi pelaku Usaha mikro, kecil dan menengah (UMKM). Sejumlah UMKM (26 juta UMKM) di Indonesia terdampak dengan adanya wabah covid-19. Namun, ada juga UMKM yang masih bertahan, diantaranya UMKM martabak surban syahwa yang berlokasi di Samarinda, Kalimantan Timur. Permasalahan yang muncul adalah, pelaku usaha masih minim pengetahuan digital marketing dan penjualan menggunakan media sosial. Untuk itulah, pengabdian kepada masyarakat dalam bentuk Kuliah Kerja Nyata (KKN) 47 Universitas Mulawarman ini dilakukan untuk memberikan pendampingan kepada UMKM Martabak Surban Syahwa agar tetap bertahan dan makin maju di era pandemi. Kegiatan dilakukan secara hibrid (daring dan luring) oleh mahasiswa dari berbagai bidang keilmuan dan dosen pendamping lapangan. Kegiatan dimulai dari koordinasi, Pelaksanaan dan evalausi. Hasil dari pengabdian ini adalah, berupa buku katalog produk, video profil UMKM, dan penjualan secara daring. Evaluasi dari kegiatan ini adalah dilakukan monitoring dan evaluasi oleh dosen pendamping lapangan dan capaian yang dirasakan oleh pelaku UMKM, adalah penjualan meningkat.
\end{abstract}

Kata Kunci: UMKM, Martabak, Pandemi, KKN, Unmul

\section{PENDAHULUAN}

Masa pandemi yang melanda lebih dari satu tahun di Indonesia telah berdampak buruk ke berbagai sektor. Sektor transportasi, pendidikan, dan ekonomi merupakan beberapa sektor yang terdampak berat di masa pandemi. Di sektor ekonomi, pandemi telah mengakibatkan penurunan daya beli masyarakat, dan berdampak pula bagi pelaku usaha, khususnya Usaha mikro, kecil dan menengah (UMKM) (Wan, 2020). Sektor UMKM ini dikabarkan mengalami kerugian yang besar akibat wabah covid-19. Sekitar 26 juta UMKM yang berada di Indonesia terdampak dengan adanya wabah virus ini (Sugiri, 2020). Bahkan diperkirakan hanya $12,5 \%$ UMKM di Indonesia yang kebal dari pandemi (Victoria, 2021).

UMKM martabak surban syahwa yang dikelola oleh Ibu Nurhayati (Pemilik), berlokasi di Samarinda, Kalimantan Timur merupakan salah satu UMKM yang masih bertahan, namun rentan dengan situasi pandemi. Hal ini dikarenakan kurangnya wawasan tentang digital marketing dan penjualan secara daring melalui media sosial. Hal ini juga didukung oleh data sebelumnya tentang kurangnya pemahaman dan pengetahuan tentang 
digital marketing para pelaku UMKM (Azilani dkk., 2015 dan Hendriadi dkk., 2019). Untuk itulah pengabdian kepada masyarakat yang diwujudkan dalam bentuk Kuliah kerja Nyata (KKN) 47 Universitas Mulawarman dilaksanakan. Kegiatan KKN oleh Universitas Mulawarman ini bertujuan memberikan pendampingan terhadap UMKM agar dapat lebih mengetahui mengenai digital marketing dan penjualan secara online. Kegiatan ini memberikan solusi kepada pelaku UMKM ini diantaranya adalah: pembuatan video profil UMKM, buku katalog menu, dan penjualan melalui media sosial (Facebook dan Whatsapp).

Dikarenakan situasi pandemi masih berlangsung dan adanya pembatasan Pemberlakuan Pembatasan Kegiatan Masyarakat (PPKM) di wilayah Kalimantan Timur, maka kegiatan ini dilakukan dengan Metode hibrid, yaitu online (daring) dan offline (luring) dengan protokol kesehatan. Kegiatan KKN secara daring, pernah dilakukan oleh KKN Universitas Mulawarman yang menyasar pada beberapa desa dan mitra (Nugroho dkk., 2020a; Nugroho dkk., 2020b, Setyowati dkk., 2021).

\section{METODE}

Kegiatan pengabdian yang diwujudkan dalam bentuk KKN 47 pendampingan UMKM ini dilakukan mulai bulan Juli hingga Agustus 2021. Kegiatan dilaksanakan oleh 4 orang mahasiswa dari berbagai bidang, yaitu: pertanian, ilmu sosial dan ilmu politik, ilmu hukum, ekonomi dan Bisnis serta dibimbing oleh dosen pendamping lapangan.

Kemitraan diawali dengan koordinasi untuk menggali masalah yang ada dengan wawancara langsung dengan pemilik UMKM, Ibu Nurhayati dan melalui media Whatsapp. Wawancara dilakukan secara langsung di rumah pemilik UMKM martabak Surban Syahwa di Jl. Pangeran Bendahara Gg. Karya Muharram RT 05 No. 11 Kelurahan Tenun, Samarinda seberang, Kalimantan Timur. Kegiatan wawancara secara langsung dilakukan dengan protokol kesehatan mengingat masih dalam kondisi PPKM Level 4.. Sementara itu, identifikasi masalah dengan Whatsapp dilakukan untuk pengiriman foto-foto dan dikumentasi lain yang mendukung dalam Identifikasi masalah. Setelah identifikasi masalah, maka dilanjutkan dengan target solusi, Pelaksanaan dan evaluasi. Adapun hal-hal yang menjadi solusi yang ditawarkan oleh tim pengabdi KKN 47 adalah:

a. Pembuatan video profil

b. Pembuatan buku katalog produk

c. Pembuatan whatsapp business

d. Promosi dengan media sosial dan integrasi dengan layanan Gofood

Gambar berikut ini adalah koordinasi dengan mitra UMKM martabak Surban Syahwa dalam program Pelaksanaan KKN 47 (Gambar 1) dan proses pembuatan video profil (Gambar 2).

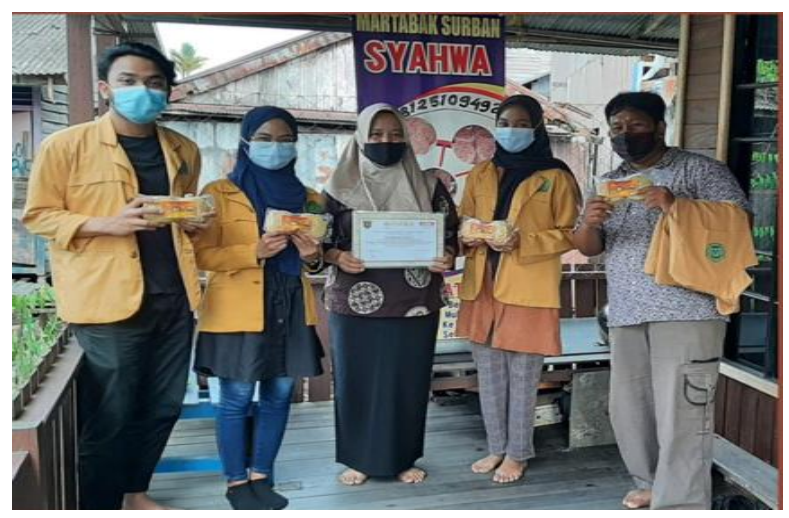

Gambar 1. Koordinasi dengan mitra/pemilik UMKM Martabak Surban Syahwa
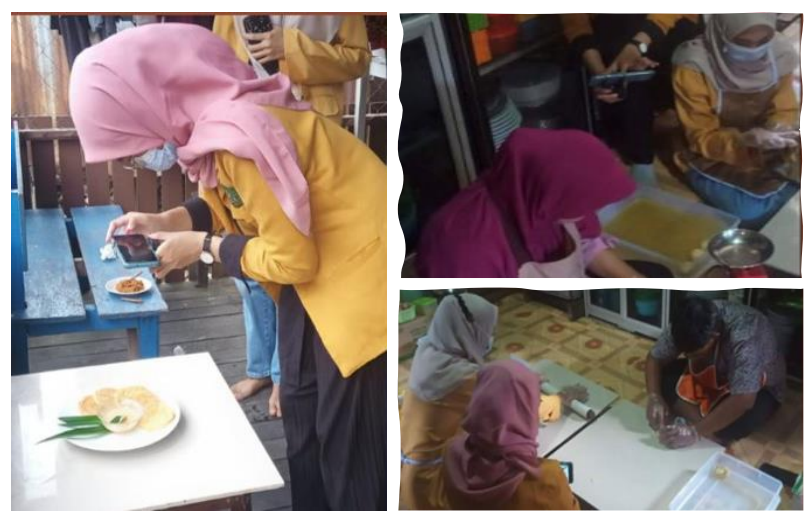

Gambar 2. Proses pembuatan video profil UMKM Martabak Surban Syahwa

Sementara itu, pelaksanaan monitoring dan evaluasi (Monev) dilakukan antara dosen pendamping lapangan dan mahasiswa pelaksanan pengabdian KKN tematik UMKM ini, untuk Identifikasi dan pelaporan kegiatan pengabdian. Kegiatan monev ini 
dilakukan secara daring dipertengahan pelaksanaan program pengabdian UMKM ini.

\section{HASIL DAN PEMBAHASAN}

Hasil dari pelaksanan pengabdian dalam wujud KKN 47 tematik kemitraan dengan UMKM ini yaitu berupa video profil (Gambar 3) UMKM Martabak Surban syahwa yang dapat diakses di tautan berikut ini: https://youtu.be/MoUzddl83B4. Pembuatan video profil ini bertujuan agar UMKM martabak syurban syahwa lebih dapat dikenal luas, dan menjangkau pembeli lain yang selama ini hanya seputaran tempat tinggal pemilik. Dengan adanya video profil yang diunggah ke akun Youtube, Instagram dan Facebook, maka informasi tentang UMKM ini menjadi lebih luas dan dapat diakses dari tempat manapun dan waktu kapanpun, sepanjang terdapat koneksi internet dan perangkat untuk mengakses.

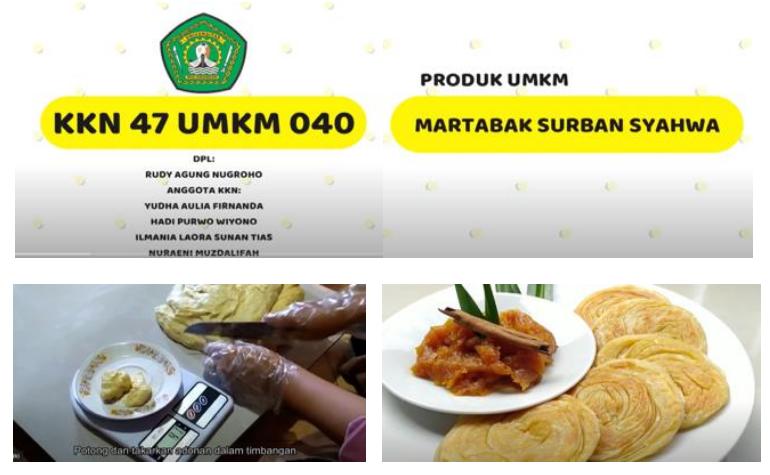

Gambar 3. Video Profil martabak surban syahwa

Sementara itu buku katalog produk (Gambar 4) juga telah selesai dikerjakan dan diserahkan kepada pemilik, serta di unggah di media sosial. Dengan adanya buku katalog ini, pembeli yang datang langsung ke lokasi UMKM dapat dengan lebih mudah untuk memilih dan melihat produk produk varian yang dijual di UMKM Martabak Surban Syahwa. Demikian pula, Ketika buku katalog ini diunggah ke media sosial, para calon pembeli dapat melihat dan membeli produk-produk martabak syurban syahwa dengan lebih mudah dan tentu saja dengan adanya buku katalog ini, menjadikan produk lebih menarik untuk dilihat dan dipesan, dampaknya adalah meningkatkan penjualan martabak syurban syahwa.
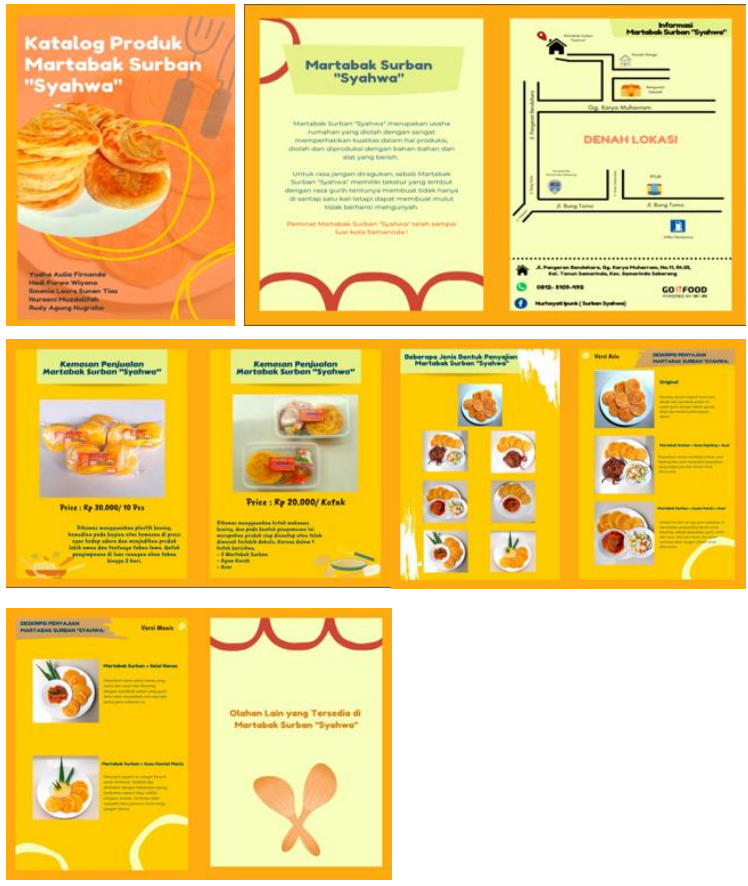

Gambar 4. Buku katalog produk martabak surban syahwa

Untuk melancarkan penjualan melalui sistem digital marketing, UMKM martabak surban syahwa ini dipromosikan melalui media sosial, yaitu Facebook (https://www.facebook.com/profile.php?id=100069 273967544), whatsapp dengan tautan (https://bit.ly/2UMGCwK) (Gambar 5), agar dapat menjangkau lebih luas lagi kepada konsumen. Model penjualan dengan layanan antar Gofood juga diintegrasikan dalam UMKM martabak surban syahwa dalam rangka mempermudah pemesanan, terutama di masa PPKM dan pandemi yang masih berlangsung. UMKM martabak surban syahwa yang tadinya hanya melayani pembeli yang datang langsung ke lokasi, sekarang ini juga menerima pesanan melalui Gofood, baik dalam partai kecil atau partai menengah, missal untuk keperluan rapat, oleh-oleh maupun kegiatan sejenisnya. 

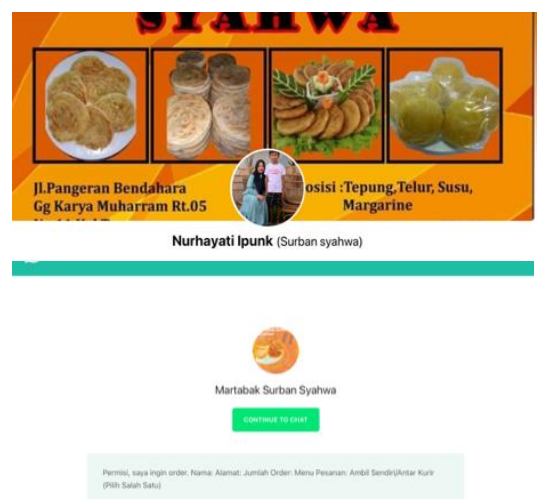

Gambar 5. Promosi melalui media sosial

Hasil dari kemitraan dengan UMKM martabak surban syahwa (Video profil dan buku katalog) setelah selesai kegiatan semua diserahkan kepada pemilik UMKM (Gambar 6) dan dapat dikelola dengan baik, agar dapat memperlancar usaha dan dapat bertahan di masa pandemi dan terus berkembang. Manfaat adanya promosi melalui media sosial seperti Instagram juga pernah dirasakan oleh UMKM lain dan memang menunjukkan dampak positif (Khairani dkk., 2018 dan Achmad, 2020). Sementara itu, evaluasi program kemitraan KKN 47 UMKM dengan mitra ini juga dimonitor dan evaluasi (Monev) oleh dosen pembimbing lapangan dan mendapatkan testimoni dari pemilik UMKM.
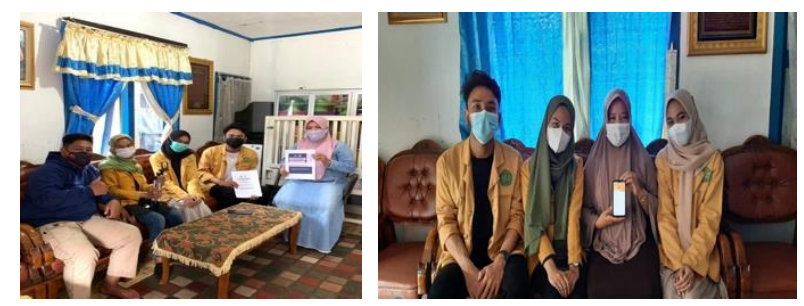

Gambar 6. Hasil Pelaksanaan KKN 47 dengan mitra martabak surban syahwa

\section{KESIMPULAN}

Kegiatan KKN 47 tematik UMKM dan bermitra dengan UMKM martabak surban syahwa telah berjalan lancar dan mendapat respon positif dari Mitra UMKM. Produk kegiatan yang dihasilkan adalah video profil, buku katalog produk, promosi melalui media sosial dan adanya respon yang positif dari pemilik UMKM. Diharapkan dengan adanya produk luaran kegiatan tersebut, UMKM ini tetap bertahan dan makin berkembang di masa pandemi dan setelahnya.

\section{UCAPAN TERIMA KASIH}

Pengabdi mengucapkan terima kasih kepada berbagai pihak yang telah mendukung kegiatan KKN 47 Universitas Mulawarman ini. Terutama, Ucapan terima kasih ditujukan kepada Lembaga Penelitian dan Pengabdian Kepada Masyarakat (LP2M) Universitas Mulawarman, dan pemilik UMKM Martabak Surban Syahwa, serta berbagai pihak yang tidak dapat kami sebutkan satu persatu.

\section{REFERENSI}

Achmad, Z. A. (2020). Pemanfaatan media sosial dalam pemasaran produk UMKM di Kelurahan Sidokumpul, Kabupaten Gresik. Jurnal Ilmu Komunikasi, 10(1), 1731.

Azliani, N., Adibrata, Y., \& Clement, Y. (2015). Strategi Pemasaran dalam Pengembangan UMKM Berbasis Kerajinan untuk Menghadapi Era Ekonomi Digital (Studi Kasus di Desa Kopo, Kecamatan Cisarua, Kabupaten Bogor). Sustainable Competitive Advantage (SCA), 5(1).

Hendriadi, A. A., Sari, B. N., \& Padilah, T. N. (2019). Pelatihan Digital Marketing Usaha Mikro, Kecil dan Menengah (UMKM) di Kabupaten Karawang. Jurnal Pengabdian Masyarakat J-Dinamika, 4(2), 120-125.

Khairani, Z., Soviyant, E., \& Aznuriyandi, A. (2018). Efektivitas promosi melalui instagram pada UMKM sektor makanan dan minuman di Kota Pekanbaru. Jurnal Benefita, 3(2), 239-247.

Nugroho, R. A., Rahmadi, A., Saputra, F. A., Nabila, R., Suratmi, S., Wardana, D. \& Laila, N. M. A. (2020). Edukasi Covid-19 dan pemberdayaan masyarakat melalui program KKN KLB, desa Kelinjau Ulu, Muara Ancalong, Kutai Timur Kalimantan Timur. In Seminar Nasional Hasil 
Pengabdian Kepada Masyarakat (pp. 1-8). ISO 690

Nugroho, R. A., Rahmadi, A., Islamiati, I., Mustari, A., Salim, M. E., Framita, E. \& Ismawati, B. M. (2021). Edukasi Pencegahan Stunting melalui Program KKN KLB 46 Universitas Mulawarman di Desa Mulupan, Muara Bengkal, Kutai Timur, Indonesia. Intervensi Komunitas, 2(2), 100-106.

Setyowati, D. L., Nugroho, R. A., \& Wiranto, A. (2020). Edukasi cegah kelelahan mata dari pengaruh gadget selama Work From Home (WFH). In Seminar Nasional Hasil Pengabdian Kepada Masyarakat (pp. 605612).

Sugiri, D. (2020). Menyelamatkan usaha mikro, kecil dan menengah dari dampak pandemi
Covid-19. Fokus Bisnis: Media Pengkajian Manajemen dan Akuntansi, 19(1), 76-86.

Victoria, A. O., (2021). Hanya 12,5\% UMKM di Indonesia yang Kebal dari Pandemi Covid19. Artikel ini telah tayang di Katadata.co.id dengan judul "Hanya 12,5\% UMKM di Indonesia yang Kebal dari Pandemi Covid-19" https://katadata.co.id/agustiyanti/finansial/6 05d9f635fdf7/hanya-12-5-umkm-diindonesia-yang-kebal-dari-pandemi-covid19. Diakses 11 Agustus 2021 Pukul 22.00 WITA

Wan, L.H. (2020). Strategi Bertahan UMKM di Tengah Pandemi Covid-19. Jurnal Akuntansi dan Ekonomika, 10(1), 89-98. 